\title{
Transoral digital reduction of complete anterior odontoid dislocation followed by fiducial-based navigated transcondylar screw fixation: illustrative case
}

\author{
Albin A. John, MBA, ${ }^{1}$ Joey Grochmal, MD, $\mathrm{PhD},{ }^{2}$ and Jason Felton, $\mathrm{MD}^{3}$ \\ ${ }^{1}$ Department of Surgery and ${ }^{3}$ Division of Neurosurgery, Texas Tech University Health Sciences Center, Lubbock, Texas; and ${ }^{2}$ Department of Neurosurgery, Baylor College of \\ Medicine, Houston, Texas
}

\begin{abstract}
BACKGROUND Posterior atlantoaxial dislocations (i.e., complete anterior odontoid dislocation) without C1 arch fractures are a rare hyperextension injury most often found in high-velocity trauma patients. Treatment options include either closed or open reduction and optional spinal fusion to address atlantoaxial instability due to ligamentous injury.

OBSERVATIONS A 60-year-old male was struck while on his bicycle by a truck and sustained an odontoid dislocation without C1 arch fracture. Imaging findings additionally delineated a high suspicion for craniocervical instability. The patient had neurological issues due to both a head injury and ischemia secondary to an injured vertebral artery. He was stabilized and transferred to our facility for definitive neurosurgical care.

LESSONS The patient underwent a successful transoral digital closed reduction and posterior occipital spinal fusion via a fiducial-based transcondylar, $\mathrm{C} 1$ lateral mass, $\mathrm{C} 2$ pedicle, and C3 lateral mass construct. This unique reduction technique has not been recorded in the literature before and avoided potential complications of overdistraction and the need for odontoidectomy. Furthermore, the use of bone fiducials for navigated screw fixation at the craniocervical junction is a novel technique and recommended particularly for placement of technically demanding transcondylar screws and C2 pedicle screws where pars anatomy is potentially unfavorable.
\end{abstract}

https://thejns.org/doi/abs/10.3171/CASE21576

KEYWORDS dens dislocation; fiducial-based neuronavigation; transcondylar screw fixation; transoral closed reduction; trauma

Posterior atlantoaxial dislocation without concomitant fracture of the $\mathrm{C} 1$ arch is a rare traumatic injury that has not been documented extensively. ${ }^{1,2}$ Of the 20 cases reported, patients did not have significant neurological deficits and their dislocation was managed with traction and supplemental fusion or fixation. ${ }^{1,3-5}$ Although the true mechanism of dislocation has not been verified, researchers postulate that the dislocation occurs due to extreme hyperextension during high-velocity trauma that permits the dens to dislocate under the $\mathrm{C} 1$ arch without the presence of fracture. ${ }^{1,3,6-8}$ Many of these dislocations are also accompanied by concomitant ligamentous injury. ${ }^{7,9}$ Here we present a unique case of dens dislocation without $\mathrm{C} 1$ fracture, managed in a controlled fashion with intraoperative, monitored, manual distraction of the neck using the Mayfield clamp, while concurrently performing transoral digital closed reduction of the odontoid dislocation. This was followed by immediate posterior stabilization using a construct consisting of transcondylar, C1 lateral mass, $\mathrm{C} 2$ pedicle, and $\mathrm{C} 3$ lateral mass screws.

\section{Illustrative Case}

\section{Presentation}

The patient is a 60-year-old male who was struck while on his bicycle by a truck. The patient had a reported Glasgow Coma Scale (GCS) score of 3 at the scene and was subsequently intubated. He was evaluated and stabilized at an outside facility with initial computed tomography (CT) imaging of the head and cervical spine demonstrating a posterior atlantoaxial dislocation as well as trace amount of intracranial subarachnoid and intraventricular hemorrhage. The patient was transferred to our facility where subsequent CT angiography of the head and neck revealed an associated right vertebral artery injury predominantly through the horizontal

ABBREVIATIONS $\mathrm{BDI}=$ basion to dens interval; $\mathrm{CT}=$ computed tomography; $\mathrm{CMF}=$ craniomaxillofacial; $\mathrm{GCS}=$ Glasgow Coma Scale; ICU = intensive care unit; $\mathrm{PICA}=$ posterior inferior cerebellar artery.

INCLUDE WHEN CITING Published January 17, 2022; DOI: 10.3171/CASE21576.

SUBMITTED October 6, 2021. ACCEPTED November 8, 2021.

(c) 2022 The authors, CC BY-NC-ND 4.0 (http://creativecommons.org/licenses/by-nc-nd/4.0/). 
segment at $\mathrm{C} 1$. Anterior dislocation of $\mathrm{C} 2$ relative to $\mathrm{C} 1$, as seen in Fig. $1 \mathrm{~A}-\mathrm{C}$, was appreciated, with the odontoid process located anterior to the $\mathrm{C} 1$ ring without evidence of fracture to either the dens or $\mathrm{C} 1$. Craniocervical instability, as evidenced by disruption of multiple stabilizing ligaments was appreciated on CT imaging with a Grabbs-Oakes measurement, basion-dens interval (BDI), and Powers ratio outside of normal limits. Further MRI, as noted in Fig. 1D and E, confirmed disruption of the vertical cruciate ligaments, the apical ligament, bilateral alar ligaments, the tectorial membrane, disarticulation of the C1-2 joints, and apparent sparing of the transverse cruciate ligament.

Prior to surgery and as a result of the vertebral artery injury, the patient suffered focal right posterior inferior cerebellar artery (PICA) ischemia seen on MRI of the brain acquired in conjunction with the cervical MRI. The MRI also demonstrated findings consistent with mild diffuse axonal injury. Our goals for surgery were to provide reduction of the dislocated dens and stabilization of the occipito-cervical junction, while maintaining access to the occipital bone in case a posterior fossa decompression became necessary.

\section{Surgery}

The surgery was divided into two stages.

\section{Stage 1}

Anterior digital transoral closed reduction of the C1-2 dislocation including reduction of the odontoid peg from its anterior location at the $\mathrm{C} 1$ arch to its anatomical position. The patient arrived at the operating room having been previously orally intubated. He was subsequently placed under general anesthesia. The endotracheal tube was repositioned laterally and taped securely as it exited from the corner of the mouth. Its position in this location did not hinder the reduction maneuvers in any manner. While in the supine position, the patient's head was secured using a Mayfield head-holder and neuromonitoring was used to assess the patient's baseline electrophysiological function. This included motor-evoked potentials, somatosensory evoked potentials, and continuous free-running electromyogram of all relevant muscle groups and the hypoglossal nerve. Manual closed reduction of the odontoid process was achieved by applying digital pressure at the posterior oropharynx where the tip of the odontoid was palpated while the neck was slightly distracted and extended through the Mayfield head-holder. The patient's reduction was closely monitored via serial electrophysiology and under fluoroscopic guidance as seen in Fig. 2. Upon confirmation that the odontoid had returned to its anatomical location, surgery progressed to stage 2.
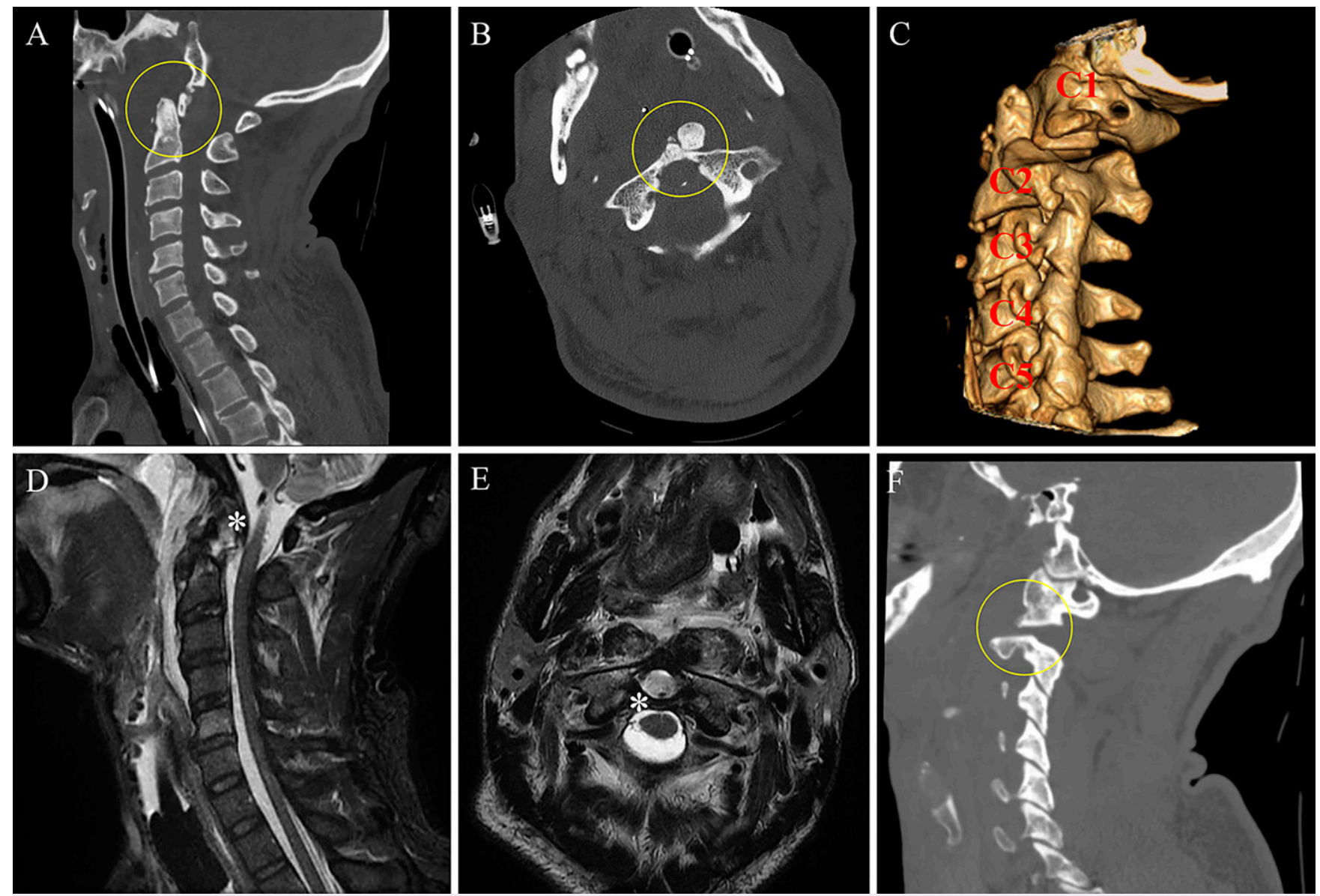

FIG. 1. There is anterior dislocation of the dens, which is positioned along the anterior border of $\mathrm{C} 1$ arch (yellow circle, $\mathbf{A}$ and B). There is a punctate ossific fragment in the region of the transverse ligament, which may represent a small avulsion fracture (B). A three-dimensional reconstruction of the cervical spine also notes the $\mathrm{C} 2$ dislocation with an intact $\mathrm{C} 1 \mathrm{arch}(\mathbf{C})$. The transverse ligament is intact $(*)$, however, the cruciate and apical ligaments along with the tectorial membrane are damaged ( $D$ and $E)$. The parasagittal image demonstrates anterior translation of the left lateral facet of $C 2$ vertebra with respect to $\mathrm{C} 1$ vertebra $(\mathbf{F})$. 

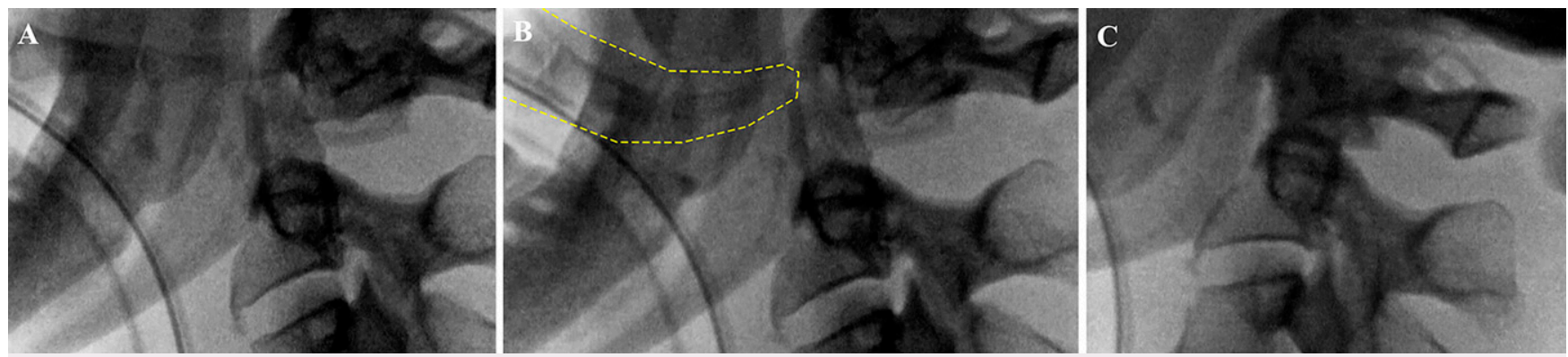

FIG. 2. The progression of closed reduction under fluoroscopy, whereby A notes total anterior dislocation of C2 and C shows complete closed reduction and dens in appropriate anatomical location. The surgeon's finger extension emphasizes the extent of pressure applied to adequately reduce the patient's dislocation (B).

\section{Stage 2}

Open posterior fracture treatment of occiput-C1 and C1-2 dissociations, removal of the posterior arch of $\mathrm{C} 1$ for decompressive purposes, arthrodesis and instrumentation from occiput to $\mathrm{C} 3$ including bicortical occipital transcondylar screws and $\mathrm{C} 1$ lateral mass screws, C2 pedicle screws, and C3 lateral mass screws as follows.

The patient was placed into a cervical collar. He was then turned into the prone position with the head and neck maintained in anatomical alignment. The Mayfield head-holder was secured to the bed. Prone-position neuromonitoring signals were repeated and maintained. The posterior occipitocervical region was identified, prepped, and draped in the usual sterile fashion after removal of the cervical collar. A midline incision from the suboccipital region to the $\mathrm{C} 3$ spinous process was created. Electrocautery and sharp dissection were used to expose the $\mathrm{C} 1$ posterior arch, the C1-2 articulations, the C2 pedicle screw entry points, and the C3 lateral masses. Subperiosteal dissection was used to expose the suboccipital region and the posterior aspect of the occipital condyles. Micro-Doppler confirmed flow in the uninjured left vertebral artery and recannulation with flow in the right vertebral artery. The patient had significant soft tissue damage posteriorly that was appreciated from the occiput to $\mathrm{C} 2$ including disruption of the posterior occipitocervical membrane. Once exposure was completed, a spinous process reference frame was secured to C2. Four Stryker craniomaxillofacial (CMF) screws were affixed to the exposed posterior elements as seen in Fig. 3 to serve as fiducials to verify accuracy during neuronavigation. Neuronavigation was achieved using the Medtronic S8 Stealth Workstation after acquiring CT imaging with the second-generation Medtronic O-arm. Intraoperatively placed bone fiducials were imperative due to the patient's challenging pars anatomy ( $<3 \mathrm{~mm}$ pars width), to facilitate placement of the transcondylar screws, and to reregister the patient in the event accuracy was compromised. All screw sites were drilled in a bicortical fashion using the navigated Midas Rex drill fit with a $2 \mathrm{~mm}$ coarse diamond bur attachment. Drilled screw trajectories were subsequently tapped, and fully threaded screws were introduced with the assistance of neuronavigation.

During each step of the procedure, the registration accuracy of the drill, tap, and screwdriver were verified by placing the tip of the instrument on the (CMF screw) fiducial marker of the segment being instrumented. If the navigated stealth image accurately demonstrated this relationship, the registration was accurately confirmed to within approximately $1.5 \mathrm{~mm}$, or the diameter of the CMF screw head. This process facilitated all navigated steps during the instrumentation by providing a high degree of confidence in the navigation accuracy. Transcondylar screws measured $4.0 \times 42 \mathrm{~mm}$ bilaterally. C1 lateral mass screws measured left $3.5 \times 38 \mathrm{~mm}$ and right $3.5 \times 36 \mathrm{~mm}$. C2 pedicle screws measured $3.5 \times 30 \mathrm{~mm}$. Lateral mass screws at $\mathrm{C} 3$ measured $3.5 \times 18 \mathrm{~mm}$. Screw placement was confirmed with anteroposterior and lateral fluoroscopy. Neuromonitoring signals did not deviate from their baseline. Finally, bilateral $3.5 \times 70 \mathrm{~mm}$ titanium rods were selected, contoured into anatomical alignment, and introduced bilaterally. This was followed by set-screw placement and final tightening under countertorque. A decompression was then performed by removing the posterior arch of $\mathrm{C} 1$. The dura was exposed, and a small dorsal epidural hematoma was removed. Proximal ventrolateral exploration of the spinal canal revealed egress of trace CSF from which a source could not be isolated. A ventral dural tear was assumed and consistent with ventral disruption of the anterior craniocervical supporting ligamentous and soft tissue structures. This area was packed with a small amount of subcutaneous fat followed by a successful Valsalva maneuver. The drill was then used to decorticate the remaining posterior elements and to complete the arthrodesis. Cadaveric
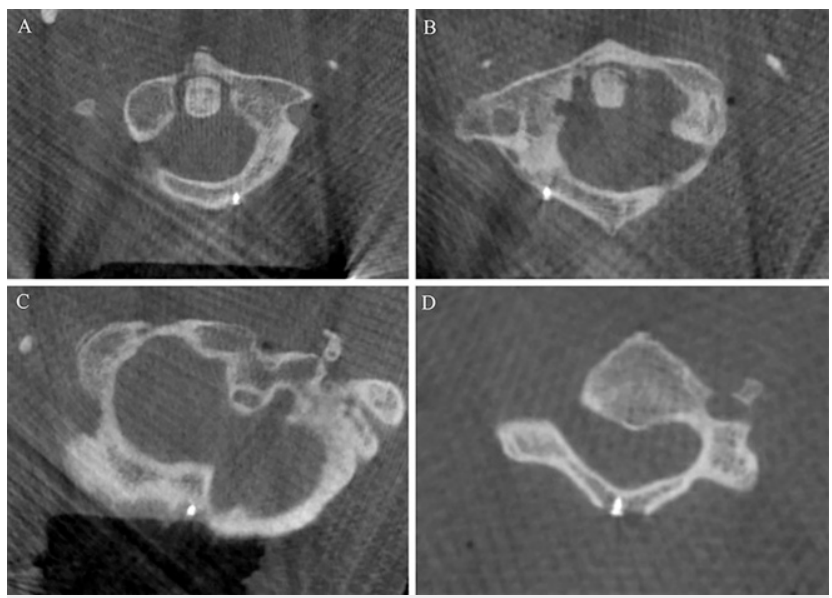

FIG. 3. The placement of CMF screws as bone fiducials for neuronavigation is appreciated on intraoperative axial CT imaging (A-D). Confirmation of high-level registration accuracy throughout the case is facilitated by placing the tip of the navigated instrument on the fiducial of the level being instrumented. 
allograft and morselized local autograft from the removal of the $\mathrm{C} 1$ posterior arch were mixed with osteogenic biological to facilitate fusion. This was applied at the $\mathrm{O}-\mathrm{C} 1$ and $\mathrm{C} 1-2$ joints bilaterally given the high rate of nonunion reported in this area ${ }^{10}$ and because removal of the posterior arch precluded supplemental wiring techniques (e.g., Gallie-Sonntag fusion). Following the removal of both the spinous process reference frame and the bone fiducials, the wound was closed in a standard layered fashion.

\section{Postoperative Course}

Postoperative CT imaging, as seen in Fig. 4, notes accurate placement of instrumentation with full reduction of the C1-2 dislocation. CT angiography of the neck showed reperfusion of right vertebral artery and stable ischemic right cerebellar focal infarct with no evidence of flow limiting stenosis in cerebral vasculature or vascular injury from screw placement.

The patient required the intensive care unit (ICU) for the following 12 days during which he had an early tracheostomy to facilitate ventilator removal and a percutaneous endoscopic gastrostomy feeding tube placed for early enteral nutrition. The patient's ICU stay was prolonged due to hospital-acquired pneumonia that was appropriately managed by the surgical ICU team. The patient was weaned from the ventilator by the end of his ICU stay. The PICA stroke did not require a decompressive craniectomy at any point. Physical examination was limited secondary to the patient's underlying cognitive issues from his acute head injury. The patient was able to localize to pain and move all extremities spontaneously and willfully but was unable to follow complex commands. The patient had good muscle tone and normal, symmetric reflexes in upper and lower extremities bilaterally. No gross cranial nerve abnormalities were noted. He was discharged to a long-term care facility.

\section{Discussion}

\section{Observations}

The vertebral column meets the skull at the junction of the occipital condyles, C1 (atlas) and C2 (axis). ${ }^{11,12}$ Along with the osteo-ligamentous ring that is formed by the transverse ligament and anterior arch of the atlas, the odontoid process, or dens, is a peg-like structure that is important in stability and rotation of the atlas. ${ }^{1,2,5,12} \mathrm{C} 1-2$ dislocation, graded using the Fielding and Hawkins classification system, occurs when the $\mathrm{C} 1$ mass displaces anteriorly relative to $\mathrm{C} 2 .^{12,13}$ These dislocations are often precipitated by extreme force traumas that can result in immediate mortality due to compression of the spinal cord. ${ }^{1,2,6,12,14,15}$ Those who are fortunate enough to survive this type of injury find themselves on the opposite end of the mortality spectrum and have few if any neurological deficits directly related to the spinal column injury. ${ }^{1,3-5}$ Nontraumatic dislocations of the dens can also occur and are due to congenital defects, metastatic tumors, and inflammatory disease. ${ }^{2,11,16,17}$ The latter type of dislocation primarily arises as a result of or erosion of the transverse ligament due to a chronic inflammatory process. ${ }^{12,16}$

Traumatic dislocations are usually anterior, due to the ligamentous barrier located dorsally, and are found in the presence of fractures of the posterior edge of the atlas's anterior arch due to the interlocking configuration of the two vertebrae. 1,6,13,17,18 Steel's rule of thirds states that one-third of the neural canal is occupied by the
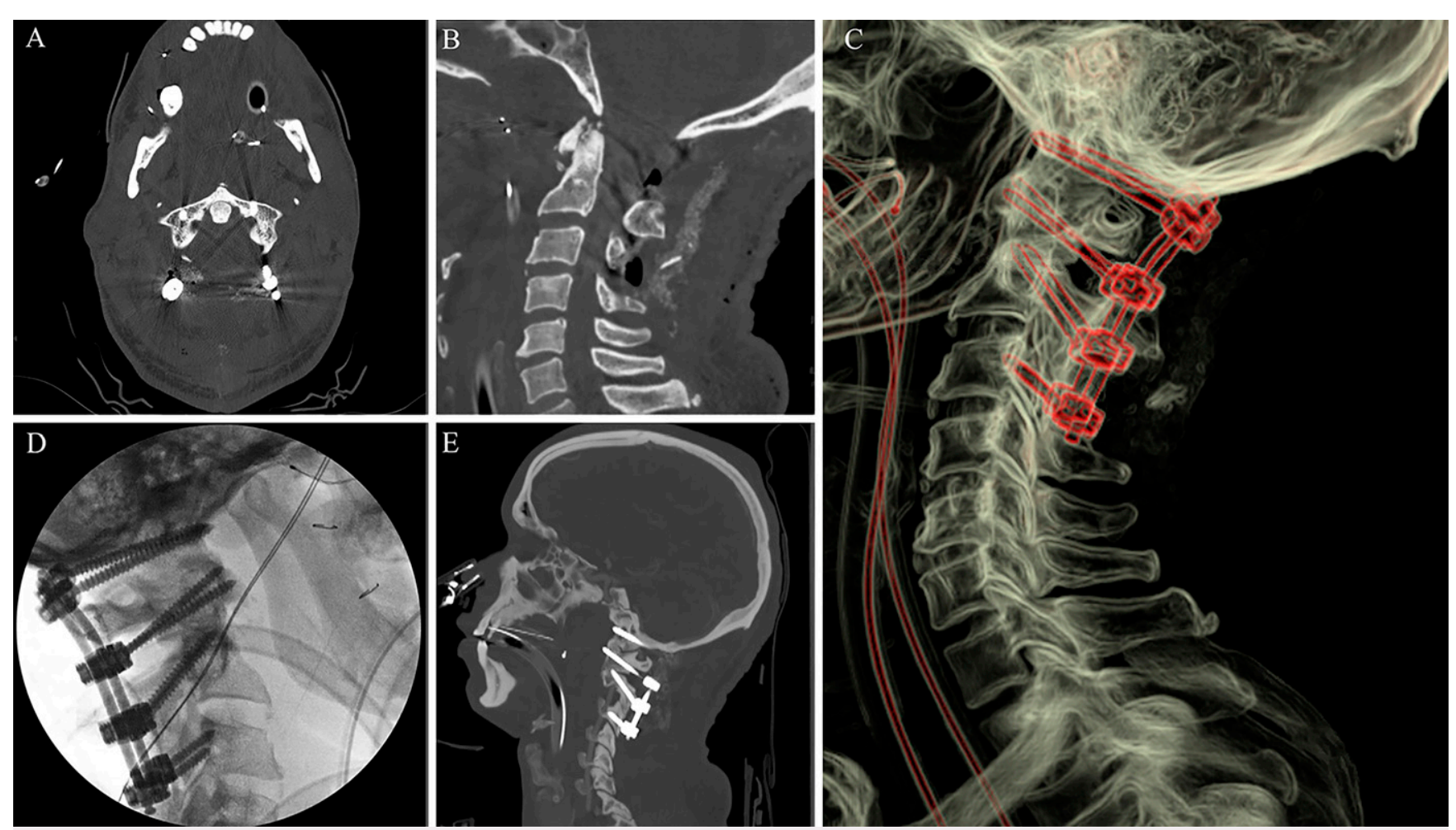

FIG. 4. The dens was adequately reduced and returned to its appropriate anatomical location after closed reduction (A and C). Appropriate postsurgical changes and evidence of $\mathrm{C} 1$ laminectomy are also appreciated (B). Posterior spinal fusion was achieved using screw placement as depicted in the render (C). Intraoperative fluoroscopy and postoperative CT imaging demonstrate condylar screw trajectory (D and E). 
dens, another one-third by the spinal cord, and the final one-third by cerebrospinal fluid. ${ }^{1}$ Therefore, during dislocation the $\mathrm{C} 1$ posterior arch will invade on the neural canal volume, with some researchers hypothesizing a decrease in neural canal of approximately $36 \%$. ${ }^{1,3,17}$ Uniquely, patients who have subluxation without fracture of the $\mathrm{C} 1$ arch are able to tolerate this dislocation and reportedly have only transient, if any, neurological manifestations of cord compression. 1,19

In traumatic cases in which there is an associated subluxation without a fracture of $\mathrm{C} 1$, the cause of injury is a rapid accelerationdeceleration mechanism that may have led to extreme hyperextension and ligamentous damage., ${ }^{2,3,6,7}$ Most of the patients recorded in the literature were neurologically intact and complained of neck stiffness or pain only. Those who had neurological deficits often had them transiently or the deficits were unrelated directly to the cervical trauma (e.g., from a concomitant head injury). ${ }^{3,6,17-20}$ The patient in this case report perhaps had a more complicated constellation of injuries than did others reported in the literature. From the intracranial hemorrhage to the vertebral artery injury and subsequent cerebellar ischemia, our patient had focal neurological deficits and gradual GCS improvement from 3 to $8 \mathrm{~T}$ prior to surgical intervention and 12 prior to discharge.

Our case is the first of those in the literature reporting concomitant craniocervical instability as a result of the disruption of multiple stabilizing craniocervical and atlantoaxial ligaments without brainstem compression. The disrupted ligaments in our case included the vertical cruciate ligament, apical ligament, and bilateral alar ligaments. These ligaments, especially the alar ligament, function to stabilize the occiput to $\mathrm{C} 1$, and disruption can imply atlantooccipital dissociation. ${ }^{21}$ The Grabb-Oakes measurement, or the measurement between the dura to a line drawn between the posterior inferior aspect of $\mathrm{C} 2$ and the basion, was $>12 \mathrm{~mm}^{22}$ Grabb-Oakes measurements above $9 \mathrm{~mm}$ imply a higher risk of brainstem compression. $^{22}$ Our patient's Powers ratio, or the ratio of distance from the basion tip to the spinolaminar line and the distance from the opisthion tip to the midpoint of the posterior aspect of the anterior arch of $\mathrm{C} 1$, was $>1.25$ with $<0.9$ considered normal. ${ }^{23}$ Last, our patient's BDI, or the distance between the basion to dens, was 15 $\mathrm{mm}$ with $<8.5 \mathrm{~mm}$ being normal. ${ }^{23}$ Intraoperative findings were also consistent with significant craniocervical soft tissue and ligamentous injury as described above.

The first-line treatment for patients with a upper cervical dislocation is an attempt at closed reduction using traction., ${ }^{7,12}$ When raising the weight of traction beyond $5 \%-10 \%$ of body weight, doing so under fluoroscopy is recommended to observe and abort the procedure should any neurological deficit arise. ${ }^{3,12,24}$ While many patients have been successfully reduced by this approach alone, $5,6,20,25-28$ overdistraction of the spinal cord and the subsequent physical manifestations have led to conversion from closed to open reduction emergently. ${ }^{3,4,17}$ Traction on an unstable craniocervical junction is fraught with risk as the already damaged ligaments no longer can counterbalance the traction thus can easily lead to traumatic distraction of the spinal cord. ${ }^{7}$ As a result, many cases include a partial odontoidectomy to reduce the distraction forces required for adequate reduction. ${ }^{1,3-5,8,17}$ Although some patients are able to achieve good stability solely with a closed reduction, ${ }^{6,26-28}$ if there was ligamentous damage or if anatomical reduction was not achieved, patients will need an open reduction/odontoid resection and stabilization by any number of established standards for C1-2 fixation and arthrodesis. $1,6,11,12,20,29$

The occipital condyle plays a major role in the stability of the craniocervical junction as it is the articulating surface with the $\mathrm{C1}$ lateral mass. ${ }^{30}$ Transcondylar screws are used for occipitocervical fusion in patients with instability, reducible atlantoaxial dislocation, significant fractures of the C1 and C2 elements, and cranial settling caused by trauma, congenital malformations, tumors, infections, or connective tissue disorders. ${ }^{30-33}$ Historically, transcondylar screws have been reserved for patients meeting one of these criteria for craniocervical instability with acquired defects of the occipital bone precluding the possibility of occipital plate application. Reports of transcondylar screw insertion in the literature are generally technical and do not report large series of patients with long-term follow-up. ${ }^{30}$

\section{Lessons}

The patient in this case had a unique surgical treatment that included controlled transoral digital closed reduction with concurrent gentle manual distraction of the neck. This was immediately followed by posterior occipitocervical spinal fusion that included transcondylar screws under guidance provided by a neuronavigational system that had accuracy confirmed in real-time by intraoperatively placed bone fiducials. The closed reduction was unique in that it used transoral digital pressure, as seen in Fig. 2, without necessitating an open anterior procedure or an odontoidectomy. In cases reviewed, a palpable mass in the posterior pharynx has been documented, however, transoral digital closed reduction was not mentioned. Therefore, an attempted combination of both distraction of the neck and anterior digital pressure may avoid extensive distraction and subsequent odontoidectomies or other complicated procedures. Second, the use of condylar screws in the context of a patient with a cerebellar stroke was imperative to provide access, in the event the patient needed an emergent decompressive suboccipital craniectomy at a later stage. Third, the use of bone fiducials as landmarks to verify accuracy during neuronavigation was a unique surgical tool used during this procedure, and the authors' recommendation for all open navigated procedures especially at the craniocervical junction where the margin of error is small and segmental motion is high. The technical elements of our surgery would have been much more challenging without the use of bone fiducials in the unstable and already mobile cervical spine. In comparison to other methods of neuronavigation mapping, the use of bone fiducials has advantages including the use of fewer points of reference (4), the ability to point reregister reliably and quickly, and the opportunity to move the reference frame without reacquiring new intraoperative imaging. Finally, drilling these narrow corridors with a navigated $2 \mathrm{~mm}$ diamond burr provides an additional level of safety especially considering the need for bicortical fixation for the transcondylar and $\mathrm{C} 1$ lateral mass screws. The authors also advocate for and routinely place bicortical subaxial lateral mass screws using the same navigation workflow and technique.

Posterior atlantoaxial dislocation without a $\mathrm{C} 1$ arch fracture is a rare injury that can present asymptomatically in high-velocity trauma patients. While few reports of similar injuries have been isolated in the literature, management of this injury commonly involves both reduction and anatomical realignment of the spine and posterior spinal fusion. This report documents a novel transoral digital closed reduction technique and a technically challenging occipitocervical fusion that employed bone fiducials for accurate navigation. These 
techniques can help surgeons successfully manage dislocations of the dens and navigate challenging anatomy with increased confidence and accuracy.

\section{Acknowledgments}

We would like to acknowledge Dr. Roy Jacob from University Medical Center Department of Radiology for imaging assistance for this manuscript.

\section{References}

1. Jiang LS, Shen L, Wang W, Wu H, Dai LY. Posterior atlantoaxial dislocation without fracture and neurologic deficit: a case report and the review of literature. Eur Spine J. 2010;19(Suppl 2):S118-S123.

2. Silbergeld DL, Laohaprasit V, Grady MS, Anderson PA, Winn HR. Two cases of fatal atlantoaxial distraction injury without fracture or rotation. Surg Neurol. 1991;35(1):54-56.

3. Hu D, Yang X, Wang J. Traumatic posterior atlantoaxial dislocation without fracture of odontoid process: a case report and systematic analysis of 19 cases. J Orthop Trauma. 2015;29(9):e342-e345.

4. Ning S, Yang S, Ding W, Ma T, Wu Z. Posterior atlantoaxial dislocation without fracture or neurological symptoms treated by transoralposterior approach surgery: a case report and literature review. Eur Spine J. 2019;28(suppl 2):37-40.

5. Jamshidi S, Dennis MW, Azzam C, Karim N. Traumatic posterior atlantoaxial dislocation without neurological deficit: case report. Neurosurgery. 1983;12(2):211-213.

6. Chaudhary R, Chaudhary K, Metkar U, Rathod A, Raut A, Sanghvi D. Posterior atlantoaxial dislocation without odontoid fracture. Skeletal Radiol. 2008;37(4):361-366.

7. Amirjamshidi A, Abbassioun K, Khazenifar M, Esmailijah A. Traumatic rotary posterior dislocation of the atlas on the axis without fracture. Report of a case and review of literature. Surg Neurol. 2009;71(1):92-98.

8. Zhen P, Lan X, Yang LW. Traumatic posterior atlantoaxial dislocation without associated fracture and neurological deficit. Arch Orthop Trauma Surg. 2011;131(5):681-685.

9. Alker GJ, Oh YS, Leslie EV, Lehotay J, Panaro VA, Eschner EG. Postmortem radiology of head neck injuries in fatal traffic accidents. Radiology. 1975;114(3):611-617.

10. De lure F, Donthineni R, Boriani S. Outcomes of $C 1$ and $C 2$ posterior screw fixation for upper cervical spine fusion. Eur Spine J. 2009;18(suppl 1):2-6.

11. Bahadur R, Goyal T, Dhatt SS, Tripathy SK. Transarticular screw fixation for atlantoaxial instability-modified Magerl's technique in 38 patients. J Orthop Surg Res. 2010;5(1):87.

12. Botelho RV, de Souza Palma AM, Abgussen CM, Fontoura EA. Traumatic vertical atlantoaxial instability: the risk associated with skull traction. Case report and literature review. Eur Spine J. 2000;9(5):430-433.

13. Sornsa-ard T, Jinlawal B, Niramitsantiphong A, Liawrungrueang $W$. Traumatic neglected atlanto-axial dislocation in pediatric: a case report. J Korean Soc Spine Surg. 2021;28(1):32-35.

14. Masalawala KS. Atlanto-axial dislocations. Paraplegia. 1977;15(2): 103-109.

15. Tucker SK, Taylor BA. Spinal canal capacity in simulated displacements of the atlantoaxial segment: a skeletal study. J Bone Joint Surg Br. 1998;80(6):1073-1078.

16. Lucas JT, Hungerford GD, Perot PL Jr. Treatment of nontraumatic atlantoaxial dislocation and fibrous fusion. Case report. J Neurosurg. 1982;56(1):139-142.

17. Sud S, Chaturvedi S, Buxi TBS, Singh S. Posterior atlantoaxial dislocation without associated fracture. Skeletal Radiol. 2002;31(9): 529-531.
18. Yoon DH, Yang KH, Kim KN, Oh SH. Posterior atlantoaxial dislocation without fracture. Case report. J Neurosurg. 2003;98(1)(suppl): 73-76.

19. Fox JL, Jerez A. An unusual atlanto-axial dislocation. Case report. J Neurosurg. 1977;47(1):115-118.

20. Wong DA, Mack RP, Craigmile TK. Traumatic atlantoaxial dislocation without fracture of the odontoid. Spine (Phila Pa 1976). 1991;16(5):587-589.

21. Joaquim AF, Patel AA. Craniocervical traumatic injuries: Evaluation and surgical decision making. Global Spine J. 2011;1(1):37-42.

22. Henderson FC Sr, Francomano CA, Koby M, Tuchman K, Adcock $J$, Patel S. Cervical medullary syndrome secondary to craniocervical instability and ventral brainstem compression in hereditary hypermobility connective tissue disorders: 5-year follow-up after craniocervical reduction, fusion, and stabilization. Neurosurg Rev. 2019;42(4):915-936.

23. Rojas CA, Bertozzi JC, Martinez CR, Whitlow J. Reassessment of the craniocervical junction: normal values on CT. AJNR Am J Neuroradiol. 2007;28(9):1819-1823.

24. Aebi M. Surgical treatment of upper, middle and lower cervical injuries and non-unions by anterior procedures. Eur Spine J. 2010;19(Suppl 1):S33-S39.

25. Haralson RH 3rd, Boyd HB. Posterior dislocation of the atlas on the axis without fracture. Report of a case. J Bone Joint Surg Am. 1969;51(3):561-566.

26. Sassard WR, Heinig CF, Pitts WR. Posterior atlanto-axial dislocation without fracture. Case report with successful conservative treatment. J Bone Joint Surg Am. 1974;56(3):625-628.

27. Patzakis MJ, Knopf A, Elfering M, Hoffer M, Harvey JP Jr. Posterior dislocation of the atlas on the axis; a case report. J Bone Joint Surg Am. 1974; $56(6): 1260-1262$.

28. Neumann U, Urbanski H, Riedel K. Posterior atlantoaxial dislocation without fracture of the odontoid. A case report. J Bone Joint Surg Am. 2003;85(7):1343-1346.

29. Bonney G. Stabilization of the upper cervical spine by the transpharyngeal route. Proc R Soc Med. 1970;63(9):896-897.

30. Bosco A, Aleem I, La Marca F. Occipital condyle screws: indications and technique. J Spine Surg. 2020;6(1):156-163.

31. Ghaly RF, Lissounov A. A modified transcondylar screw to accommodate anatomical skull base variations. Surg Neurol Int. 2017; 8(1):98.

32. Uribe JS, Ramos E, Vale F. Feasibility of occipital condyle screw placement for occipitocervical fixation: a cadaveric study and description of a novel technique. J Spinal Disord Tech. 2008;21(8): 540-546.

33. Lu DC, Roeser AC, Mummaneni VP, Mummaneni PV. Nuances of occipitocervical fixation. Neurosurgery. 2010;66(3)(suppl):141-146.

\section{Disclosures}

Dr. Grochmal reported personal fees from Stryker and personal fees from Ulrich outside the submitted work. No other disclosures were reported.

\section{Author Contributions}

Conception and design: Grochmal, Felton. Acquisition of data: John, Felton. Analysis and interpretation of data: Felton. Drafting the article: John, Grochmal. Critically revising the article: all authors. Reviewed submitted version of manuscript: all authors. Approved the final version of the manuscript on behalf of all authors: John. Administrative/ technical/material support: Felton. Study supervision: Felton.

\section{Correspondence}

Albin A. John: Texas Tech University Health Sciences Center, Lubbock, TX. albin.john@ttuhsc.edu. 